\title{
Differences in Experiences With the Development of Mixed-Use Projects From 2004 and 2017
}

\author{
Jamie Metzinger * \\ Indiana State University, Construction Management, Terre Haute, IN, United States
}

Mixed-use developments, having three or more uses within one development, have several benefits for communities, however due to the complexity of these developments, several challenges arise in the planning and development phases. The main challenges are local regulations, neighborhood opposition, financing, and insufficient market interest. A 2004 survey of these challenges was repeated in 2017 and the differences between the two are compared in this paper. Significant differences were found in the frequencies of the challenges, mainly that the proportion has dropped in 2017. However, local regulations remained the most significant challenge encountered. The decrease in frequencies is conceivably a sign that regulators, financers, and members of the community are becoming more familiar with mixed-use developments.

OPEN ACCESS

Edited by:

Zhen Chen,

University of Strathclyde,

United Kingdom

Reviewed by:

Jonathan Levine,

University of Michigan, United States

Maged Zagow,

Galala University, Egypt

*Correspondence:

Jamie Metzinger

jamie.metzinger@indstate.edu

Specialty section:

This article was submitted to

Construction Management,

a section of the journal

Frontiers in Built Environment

Received: 30 June 2021 Accepted: 06 September 2021 Published: 23 September 2021

Citation:

Metzinger J (2021) Differences in Experiences With the Development of Mixed-Use Projects From 2004

and 2017.

Front. Built Environ. 7:734149. doi: 10.3389/fbuil.2021.734149
Keywords: mixed-use development, regulations, neighborhood opposition, market interest, financing

\section{INTRODUCTION}

Mixed-use development, multiple uses within a project, although not a new concept, is continuing to grow in popularity. Mixed-use development has several benefits for communities and is a key strategy in achieving sustainable environments (Woo and Cho, 2018). It has been utilized as a popular method for community revitalization, helping to increase density which helps grow communities with limited land space or empty city centers and create a vibrant space for people to enjoy. Additionally, the developments provide benefits to the environment, retailers, residents, and municipalities. Increasing the walkability of an area can reduce commuting distance and auto mode share (Lee, 2020) and thus reduces pollution. Offices and retailers within a mixed-use development become immersed in potential customers from the diverse residents and other businesses (Chinburg Properies, n.d; Slowly, 2016). Because amenities are closer to home, mixed-use developments promote walking, which provides health benefits for residents (University of Delaware De). Further, it is estimated that nearly 33\% of people would prefer to live in a diverse, walkable community (Slowly, 2016). Municipalities see a tax revenue in-crease from mixed-use versus single use and are able to save on infrastructure construction, such as roads and water supply, because of the shared land use (University of Delaware De; Newcomb, 2015; Lamb, 2012; Useful Community Developm, 2017). Any one of these assets would be a reason to promote mixed-use development, to say nothing of simply overcoming obstacles to its provision. In combination, they form a compelling case for mixed use as an element of a more inclusive and prosperous society.

Levine and Inman used the Urban Land Institute definition of mixed-use developments as having three or more uses in one project (Urban Land Institute, 2011; Levine and Inam, 2004) as this very premise makes mixed-use developments popular, it also creates challenges. Zoning, building codes, and appropriate uses are some of the prominent challenges developers face when planning this type 
of project. Transferring one development's successful practices to another development rarely result in the same outcomes. For this reason, it has proven difficult to determine best practices for these types of projects.

In 2004, Levine and Inam (2004) from the University of Michigan performed a nation-wide survey of developers to determine the highest impact challenges to mixed-use developments. The present study has recreated the survey to determine if there are significant changes in challenges to the use of mixed-use developments in 2017. Further, the current survey also collected the opinions of planners, architects and construction managers as they are the stakeholders most involved with the upfront planning processes involved for mixed-use development and represent their own aspects, opinions, and goals for the success of the project. This study aims to answer the following questions:

- What are the current factors affecting mixed-use development as perceived by developers, planners, architects, and construction managers?

- What are the differences in the factors of local regulation, market interest, financing, local opposition, in a survey of developers in 2004 (Levine and Inam, 2004) and 2017?

\section{METHODS AND MATERIALS}

\section{Literature Review}

Mixed use development has become a popular tool to revitalize communities, increase sustainability, and develop a stronger sense of community. The exact definition of mixed-use development is relative from country to country (Lau et al., 2005). In the United States, the Urban Land Institute (Urban Land Institute, 2011) defines mixed-use as "three or more significant revenue-producing uses (that have a) functional and physical integration of project components" (p. 2). AdditionallyLau et al. (2005) suggest that no single-use should utilize more than two-thirds of the usable floor plan of the project. The potential uses for the project include "real estate with retail, office, residential, hotel, recreation, or other functions that are pedestrian-oriented" (Rabianski et al., 2009) (p. 206). These uses encompass the popular live-work-play environment for people where everything needed is comparatively close. However, despite these definitions, one mixed-use development approach and plan rarely results in the same success amongst various projects; this is due to the various ways in which mixing uses may be applied.

According to Grant (2002), there are three main ways that a community may apply mixed-use: increasing the intensity of land uses, increasing the diversity of uses, and integrating segregated uses. Intensity of land use is known as the variety of choices of a specific type of use; multiple types of retail or housing choices to accommodate all levels of income (Niemira, 2007). Projects may be as large as entire neighborhoods, an entire street or block, or as small as an individual building; located in inner city or city centers, brownfield or greenfield sites, or city edges such as suburbs (Rowley, 1996). These projects are typically implemented as an attempt to promote mixed use developments through "1) conservation of established mixeduse settings; 2) gradual revitalize and incremental restructure of existing parts of towns, such as infill development and reuse, conversion and refurbishment; and 3) comprehensive development or redevelopment of larger areas and sites" (Rowley, 1996) (p. 87). Table 1 summarizes the variables of these factors.

These various factors and their options of mixed-use give more credence to the idea that the same urban form may not be successful in another development; yet can be adaptable as needed, provided the proper planning is performed. This also shows that mixed-use development can occur on several different scales and can intertwine together in various environments; thus, a critical analysis should be performed to determine the best approach to incorporate the proper setting, location, and timing.

As mixed-use developments have evolved, so has their popularity. Rowley (1996) points out that due to the diversity of the urban setting, experiences are different than in suburban or rural settings, such as "people, activities, uses, architecture; the amenities, open spaces and other visual stimuli that cities can offer; and a rich public life" (p. 89). Further, many of these services, including retail and public transit, rely on a higher density in or-der to function (Brewer and Grant, 2015). In a survey from four real-estate associations, the top three reasons cited for the popularity in 2006 were: "the live-work-play environment as a single location is convenient; rising land prices are making more density necessary; and the format is being encouraged by local public agencies" (Niemira, 2007) (p. 54). While there are individual benefits to mixed-use development, there are community-wide benefits as well. Hoppenbrouwer and Louw (2005) report that the most significant advantages of mixed-use development are a reduction in travel needs, followed by increased urban diversity, and vitality.

Mixed-use developments generate economic vitality (MahmoudiFarahani et al., 2018) benefits for businesses. Job creation is a strong sign of vitality and a main goal of mixeduse development is mixing residences and offices to provide easy access to employment and clients (Grant, 2002; Hoppenbrouwer and Louw, 2005; Grant and Perrott, 2011; Kong et al., 2015). Businesses actually prefer to be in mixed-use as some of their client-base is already created just by proximity (Chinburg Properies, n.d; Slowly, 2016); for example when stadiums or arenas are in the community, there are " 50,000 people will want to have something to do before and after the game other than hangout in the parking lot" (Slowly, 2016) (para 9). Even on a smaller scale, a community with a theater or playhouse has the same need, employees have a place for lunch, entertainment, and so on (Efficient Gov, 2015). Diverse uses attract more and diverse people, providing an increased potential for the business to be seen rather than with an isolated location (Chinburg Properies, n.d; Slowly, 2016; University of Delaware De). Further, property managers tend to provide better service as they have more clients within a building, resulting in quicker response to issues, preventative maintenance, and lower costs from sharing the building with other inhabitants (Chinburg Properies, n.d; 
TABLE 1 | Factors and variables for the application of mixed-use development.

\begin{tabular}{ll}
\hline Factors & Districts or neighborhoods \\
\hline Settings & Street or other public spaces \\
& Building or street blocks \\
& Individual buildings \\
& City or town lefts \\
Inner-city or Brownland \\
Locations & Guburban or edge of town locations \\
& Greenfield locations \\
& Conservation of established mixed-use settings \\
Approaches & Gradual revitalization and incremental restructuring of existing parts of towns, including infill development and reuse, \\
& conversion and refurbishment \\
& Comprehensive development or redevelopment or larger areas and sites \\
& Varying schedules and reasons \\
Time & Space sharing for activities
\end{tabular}

Adapted from "Mixed-use Development: Ambiguous concept, simplistic analysis and wishful thinking?" by Rowley 1996, Planning Practice and Research, 11 (1), 85-98 (Rowley, 1996).

Buildings, 2009). If successful, profits for businesses in mixed-use communities can exceed traditional locations by three times, sometimes more (Leonard and Cumbelich, 2014).

Regulations are required for infrastructure maintenance and economic support. Roads, water supply, drainage, etc. are built to a specific capacity and if these capacities are exceeded they can break down faster, require more maintenance, or may not work at all; thus planners are often unable to accommodate all development requests of higher density. Additionally, uses are regulated by zoning in order to not saturate the market, preserve history, or not disturb residents. One jurisdiction may have different objectives and purposes or different views how to reach them in another district. Besides counties, jurisdictions could also be cities. Each jurisdiction has a committee of people from the community that approves regulations, zoning changes, land use, and construction. These planning committees are led by planners who are professionals that are employed by the city or county in order guide the committee that make decisions on these regulations (City planning, 2016).

Planning staffs and commissions do not always support the mixed-use concept. In interviews performed by Grant (2002), the researcher found that planners of smaller communities hesitate to utilize mixed-use as they doubt the benefits. Instead, they believe that existing neighborhoods need support and that people choose the suburbs for, among other benefits, the separation from other uses. Rowley (1996) suggests that some planners make uninformed assumptions about the community's wants and needs. Further, they underestimate the implications of these assumptions. On the other hand, Brewer and Grant (2015) suggest some planners promote density as a way to increase services within the community; however, their execution is lacking. The thought is that increased density leads to lower housing costs and better support of mixed-use; however, actual the actual populations do not meet expectations. Therefore, services do not have the expected support, resulting in the loss of the anticipated benefits associated with mixed-use development.

Another hurdle in successful mixed-use is identifying proper compatibility of uses. This includes compatibility for community and other uses in the area; Rabianski et al. 2009 describes this as creating a synergy in the community. For proper integration and increased vitality, a market analysis for each use is needed to ensure relevant uses, scale, and location (Anders, 2004; Rabianski et al., 2009). Taleai et al. (2007) found that uses and land types can actually "repel" other uses. For example, although highways provide accessibility, they also create noise which can be problematic for residences (Taleai et al., 2007). Similarly, other competing or over-saturated businesses and uses should be avoided, instead uses should be complementary. Rowley (1996) describes other factors that affect people using mixeduse developments such as having accommodations for the disabled and elderly, various levels of income, and convenience of use. In order to maximize infrastructure savings, space should be designed to be used as often as possible, including outside of normal business hours (Rabianski et al., 2009). In a diverse area, individual schedules can vary greatly resulting in varying times of usage needs. Rowley (1996) suggests sharing spaces, especially for uses that may not otherwise be able to afford the space on their own; for example a building room may host an aerobics class in the morning, a book club in the afternoon, and a card club in the evening. This type of space sharing helps to further maximize available uses and amenities for the community.

Although many people prefer mixed-use city life, there are as many others who do not wish to live in the city. And, while people enjoy the conveniences that mixed-use development offer, some are very cautious about what uses should be mixed. For example, uses such as "group homes, day care centers, waste management facilities, high-density housing, halfway houses, or prisons typically encounter resistance from residents. Even parks and playgrounds sometimes met opposition" (Grant, 2002) (p.73). Brewer and Grant (2015) point out that attempts to increase population densities and mix are affected by household dynamics. For instance, families prefer homes with gardens, that allow privacy for peace and quiet, offer some separation, and provide community-focused amenities (Rowley, 1996). For a long time, the American dream included a home in the suburbs with a white picket fence and living among people 
who are nearly the exact same, which goes against urban mixedused development. However, even in 1996, Rowley notes that social networks are only partly shaped by the home locality, mostly dependent on personal mobility, "convenience, choice, and price" are the main factors of determining shopping. Technology since then, such as the internet, hand-held devices, and social media, has developed strong social networks that are not even in the same state. At the same time, mobile applications such as Uber rideshares have made it easier to live without a car, making urban living even more accessible. These cultural variables can differ in intensity from area to area, making research even more indispensable for planning. Determining the best use of space to attract the most people is integral to mixed-use development.

In addition to the comprehensive pre-construction planning process and challenges, there are challenges during design phases as well. All construction must comply with local building codes, however with mixed-use development, each use may be subject to a different code which can slow production and add cost. Additionally, each use requires its own support system; for example, it is necessary for a restaurant to have an isolated exhaust system from the rest of the building, and retailers do not want apartment plumbing pipes visible in their space (Koch, 2004). For each use, building codes require different fire suppression methods, and in a mixed-use these can become even more stringent (Rowley, 1996) due to the mixture and higher density. Furthermore, structural safety can become challenging as well. Retail space is more open and expansive than residential or office spaces. Typically retail is on the ground floor for easy access to shoppers, thus the ceiling of this space must be designed to support the above load. As retailers prefer to have minimal columns in or-der to maximize space and have unobstructed views, a support beam must be utilized. This is very expensive as is requires engineered support beams and more material for construction (Koch, 2004).

Although mixed-use development can help to diffuse economic risk across the variation of uses, there are several economic risks which can detract developers from attempting innovative mixed-use projects (Grant, 2002). As Grant and Perrott (2011) point out, construction costs for these projects are higher than single-use construction, however they do not always generate a sales premium (Rowley, 1996; Koch, 2004; Niemira, 2007). Unfortunately, people outside of the construction process do not always understand what adds costs to projects and therefore do not prefer the premium sales price. During an interview, a principal from Elkus/Manfredi Architects, LTD. stated that mixed-use projects can cost as much as $70 \%$ more than in an average suburb (Koch, 2004) where most uses are separated by building. Furthermore, a survey byNiemira (2007) revealed that almost $2 / 3$ of respondents agreed that mixed-use projects have a longer construction time than that of separate components. The longer a construction project lasts, the more expensive it becomes as day to day overhead expenses accrue and cannot be re-covered. Furthermore, investors see mixed-use projects as less prosperous than single-use ones that consequently have a lower exchange value (Rowley, 1996).

However, there are variables which, when present, further increase the chance of success, specifically economic success.
Financial returns have the capability to be higher in more dense neighborhoods as they provide more opportunities to accept a mixed-use project. However, smaller cities can lack these drivers of change created from high levels of population influx. Thus, in these cities, more research should be performed to determine the proper economic, market, and political conditions to accept a mixed-use development (Brewer and Grant, 2015). Niemira (2007) survey results, suggests that there are three major factors for financial success: "1) having a major draw-employers, an academic institution, an entertainment facility; 2) developing the project as part of a master-planned site; and 3) having an urban location" (pp. 55-56). Being aware of the unique economic environment in which the project will be constructed will only help to increase the chances of making the development more profitable and attract more investors.

Although there is a consensus on various factors that affect success, previous attempts to utilize explicitly defined best practices have regularly not resulted in the same levels of success from project to project. Further adding to the difficulty of administering best practices, it is difficult to quantify them for a specific area until perceived differences are identified (Hoppenbrouwer and Louw, 2005). Rowley (1996) states that mixed-use development "cannot be divorced from cultural priorities and lifestyles” (p. 85). Moore (Koch, 2004) explains that, especially with mixed-use development, implementation depends on culture, context, etc., therefore best practices are not necessarily transferrable. According to Kong et al. (2015), this means that "different urban forms generally lead to different urban performance" (p. 95). Each project should be guided by the community's social make-up and not assumed that it will revitalize the community as it did in another community (Anders, 2004) nor that all residents within the community will benefit from the project (Grant, 2002).

Although significant challenges in planning and completing mixed-use developments exist, there are several instances of successful projects. Taleai et al. (2007) state the im-portance of planning, which includes analyzing the current market and defining any potential problems. Extensively engaging the community as early as possible (Anders, 2004) also helps to determine market conditions and overcome problems more efficiently. Market analysis includes identifying both successful and competing uses (Taleai et al., 2007). Many agree that location is important as mixed-use performs better when there is more traffic (Grant and Perrott, 2011) and public transportation is within walking distance (Niemira, 2007). Timing is also important as there needs to be enough people to support retail, yet enough businesses to attract people; thus phasing based on community needs is vital to success (Grant and Perrott, 2011).

In an interview by Koch (2004), a president and managing partner of a real estate developer in North Carolina said that to draw people towards the development, he reserves the most visible, ground level portion of buildings for most attractive retailers. Similarly, Niemira (2007) survey showed that including a major draw, such as employers, an academic institution, entertainment, etc., is the number one factor in achieving financial success. The second and third results from 
TABLE 2 | Challenges encountered to mixed-use development 2004 (Levine and Inam, 2004).

\begin{tabular}{lcc} 
& Frequency & Percent \\
\hline Local regulations & 531 & $76.6 \%$ \\
Neighborhood opposition & 404 & $58.3 \%$ \\
Financing & 239 & $34.5 \%$ \\
Other & 195 & $28.1 \%$ \\
Insufficient market interest & 178 & $25.6 \%$
\end{tabular}

Respondents can select more than one challenge. $\mathrm{n}=693$.

TABLE 3 | Challenges encountered described as "other" (Levine and Inam, 2004).

\begin{tabular}{lcc}
\hline & Frequency & Percent \\
\hline Land availability & 47 & $24.1 \%$ \\
Cost & 35 & $18.0 \%$ \\
Developer interest & 22 & $11.3 \%$ \\
Public understanding and acceptance & 20 & $10.3 \%$ \\
Transportation and infrastructure & 12 & $6.2 \%$ \\
Policy maker understanding and acceptance & 10 & $5.1 \%$ \\
Financial risk & 8 & $1.0 \%$ \\
Unproven nature of projects & 2 & $20 \%$ \\
Miscellaneous & 39 & - \\
\hline Total & 195 & $100 \%$
\end{tabular}

TABLE 4 | Frequency of most significant challenge 2004 (Levine and Inam, 2004).

\begin{tabular}{lcc} 
& Frequency & Percent \\
\hline Local regulations & 289 & $42.6 \%$ \\
Neighborhood opposition & 119 & $17.5 \%$ \\
Other & 107 & $15.8 \%$ \\
Insufficient market interest & 102 & $15.0 \%$ \\
Financing & 62 & $9.1 \%$ \\
Total & 679 & $100 \%$ \\
Did not answer & 14 & - \\
\hline Total & 693 & - \\
\hline
\end{tabular}

the same survey were being part of a master plan and being in an urban location, respectively. Niemira (2007) also found that "almost $60 \%$ of industry players and observers who participated in the survey felt that having public-sector involvement in a mixed-use project would help to make it more financially viable" (p. 55).

\section{Levine and Inam 2004 Results}

In Levine and Inam (2004) mailed 2,000 surveys to members of the Urban Land Institute. Of the 2,000 surveys, 706 were returned completed and 693 were qualified providing a $36.5 \%$ response rate.

The next four tables summarize the main results obtained by Levine and Inam (2004), related to the use of mixed-use development in 2004. Table 2 summarizes the challenges encountered by the respondents in 2004 and respondents were able to select more than one challenge and write in a challenge that was not listed. The next table, Table 3 summarizes the designation of "Other" written in. Instead of asking to rank all challenges, the 2004 survey asked two separate questions, the first
TABLE 5 | Frequency of second most significant challenge 2004 (Levine and Inam, 2004).

\begin{tabular}{lcc} 
& Frequency & Percent \\
\hline Neighborhood opposition & 226 & $34.3 \%$ \\
Local regulations & 204 & $31.0 \%$ \\
Financing & 121 & $18.4 \%$ \\
Insufficient market interest & 55 & $8.4 \%$ \\
Other & 52 & $7.9 \%$ \\
\hline Total & 658 & $100 \%$ \\
\hline Did not answer & 35 & - \\
\hline Total & 693 & -
\end{tabular}

asking to provide the single most significant challenge, the next question asking to provide the second most significant challenge (Tables 4, 5). Local regulations was the most significant challenge with the highest frequency, followed by neighborhood opposition, "other", insufficient market interest, and secure financing. Neighborhood opposition was the second most significant challenge with the highest frequency, followed by local regulations, secure financing, in-sufficient market interest, and "other".

\section{Methods}

This research used a quantitative approach through the use of a survey instrument. The population for this study was United States organizations involved in the preplanning process of mixed-use projects, these include architects, city planners, developers, and construction managers.

The survey instrument developed for this survey is greatly inspired by Levine and Inam (2004) instrument. Demographic questions were added to the current survey:

- Please tell us about the industry function you are involved with.

- A map was added to determine geographic region.

- How many years of experience does your organization have dealing with mixed-use projects?

The main questions that remained the same between the two surveys:

- What, if anything, do you think are significant barriers to the further development of these alternatives?

- Which of the barriers above what is the most significant and second most significant single obstacle to further development of these alternatives.

Questions were then added about the change of the challenge, if its significance had increased, decreased, or remained the same.

The survey questions were included in an online surveying platform (Qualtrics) and distributed to U.S. based organizations. Organizations were asked to send the survey out to their members, including American Institute of Contractors, American Planning Association, Association for the Advancement of Cost Engineering, Next City, United States Green Building Council; the members of the Purdue University School of Construction Management contact list 
were emailed directly. Additionally, in the invitation email, participants were asked if they could forward the invitation to other stakeholders, there-fore snowball sampling was also used. Additionally, the survey was also publicly posted in LinkedIn via personal profiles.

The research questions to be answered by the survey are:

- What are the current factors affecting mixed-use development as described by developers, planners, architects, and construction managers?

- What are the differences in the factors of local regulation, market interest, financing, local opposition, in a survey of developers in 2004 (Levine and Inam) and 2017?

Responses to the encounters and significance of the challenges were coded either yes or no. If the respondents had encountered the challenge, yes was coded, or no if not. Chi square tests were completed to test the proportional frequencies from the 2004 answers compared to the 2017 answers. However, the ranking of first and second most significant challenge was not tested individually, but as the overall ranking of all challenges.

TABLE 6 | Frequency of role of respondents.

\begin{tabular}{lcc} 
Role & Frequency & Percent \\
\hline Planner & 3 & $2.8 \%$ \\
Developer & 6 & $5.6 \%$ \\
Construction Manager & 64 & $59.8 \%$ \\
Architect & 34 & $31.8 \%$ \\
\hline Total & 107 & $100 \%$
\end{tabular}

TABLE 7 | Challenges encountered to mixed-use development.

\begin{tabular}{lcc}
\hline & Frequency & Percent \\
\hline Local regulations & 54 & $50.5 \%$ \\
Financing & 40 & $37.4 \%$ \\
Neighborhood opposition & 40 & $37.4 \%$ \\
Other & 18 & $16.8 \%$ \\
Insufficient market interest & 14 & $13.1 \%$
\end{tabular}

Respondents can select more than one challenge. $\mathrm{n}=107$.

\section{RESULTS}

\section{Descriptive Statistics}

Table 6 shows the distribution of the roles of the 107 respondents. Both Construction Managers $(n=64)$ and Architects $(n=34)$ had a higher response rate than other stakeholders. Unfortunately, the reach to Developers $(n=6)$ and Planners $(n=3)$ was lower than expected. Because it is unknown which organizations actually distributed the email, it is impossible to know the response rate, however, based on responses, it is assumed low.

The initial question regarding challenges to mixed-use development asked for all challenges and barriers encountered, Table 7 summarizes the responses. For this question, respondents could select more than one answer and write in a response not provided. Local regulations is the most frequently selected challenge with 54 selections, followed by financing and neighborhood opposition, each selected 40 times. Insufficient market interest is the least frequently chosen with only 14 selections. The "other" option was selected 18 times with challenges written by respondents, Table 8 provides the designation for these selections.

When asked to rank the challenges in Table 7 from one to five with one being the most significant and five being the least significant, 64 of the respondents participated. The frequency of the ranking of each challenge can be seen in Table 9.

\section{Analytical Statistics}

It is important to note that not only is there potential for change over time, but between the two populations. In 2004, Levine and Inam (Levine and Inam, 2004) were able to reach developers, however in 2017 the same population was not able to be reached and resulted in mostly construction managers and architects.

The survey asked respondents to rank their first and second most frequent challenge; these responses can be seen in (Tables 10, 11). The survey question asking which challenges were encountered by respondents (Table 7) was compared to the similar question from the survey in 2004 (Table 12) to answer the second research question "What are the differences in the factors of local regulation, market interest, financing, local opposition, and possibly others to a survey of developers in 2004 and 2017?" Table 12 summarizes the data. Local regulations remains the most frequently encountered.

TABLE 8 | Challenges encountered described as "other".

\begin{tabular}{|c|c|c|}
\hline- & Frequency & Percen \\
\hline Construction cannot occur fast enough to keep up with demand and growth & 4 & $22.2 \%$ \\
\hline Financial risk & 3 & $16.6 \%$ \\
\hline Market saturation & 2 & $11.1 \%$ \\
\hline Lack of land/land cost & 1 & $5.5 \%$ \\
\hline Complexity of construction and design & 1 & $5.5 \%$ \\
\hline Lack of implementation knowledge & 1 & $5.5 \%$ \\
\hline Developer interest & 1 & $5.5 \%$ \\
\hline Harder for small firms & 1 & $5.5 \%$ \\
\hline No retail involvement & 1 & $5.5 \%$ \\
\hline Project type not the norm & 1 & $5.5 \%$ \\
\hline Total & 18 & $100 \%$ \\
\hline
\end{tabular}

Respondents can select more than one challenge. 
TABLE 9 | Current frequencies of challenges rankings.

\begin{tabular}{|c|c|c|c|c|c|c|c|c|}
\hline \multirow[t]{2}{*}{-} & \multicolumn{2}{|c|}{$\begin{array}{l}\text { Insufficient market } \\
\text { Interest }\end{array}$} & \multicolumn{2}{|c|}{ Local regulations } & \multicolumn{2}{|c|}{ Secure financing } & \multicolumn{2}{|c|}{$\begin{array}{l}\text { Neighborhood } \\
\text { opposition }\end{array}$} \\
\hline & Freq & Percent & Freq & Percent & Freq & Percent & Freq & Percent \\
\hline 1 Most Significant & 11 & $17.2 \%$ & 22 & $34.4 \%$ & 14 & $21.9 \%$ & 9 & $14.1 \%$ \\
\hline $2-$ & 7 & $10.9 \%$ & 21 & $32.8 \%$ & 14 & $21.9 \%$ & 19 & $29.7 \%$ \\
\hline $3-$ & 15 & $23.4 \%$ & 14 & $21.9 \%$ & 20 & $31.3 \%$ & 15 & $23.4 \%$ \\
\hline $4-$ & 24 & $37.5 \%$ & 0 & $0 \%$ & 15 & $23.4 \%$ & 18 & $28.1 \%$ \\
\hline 5 Least Significant & 7 & $10.9 \%$ & 7 & $10.9 \%$ & 1 & $1.6 \%$ & 3 & $4.7 \%$ \\
\hline Total & 64 & $100 \%$ & 64 & $100 \%$ & 64 & $100 \%$ & 64 & $100 \%$ \\
\hline Mean & 3.14 & - & 2.09 & - & 2.61 & - & 2.8 & - \\
\hline SD & 1.271 & - & 1.003 & - & 1.121 & - & 1.143 & - \\
\hline
\end{tabular}

TABLE 10 | Current Frequency of most significant Challenge.

\begin{tabular}{lcc}
\hline- & Frequency & Percent \\
\hline Local regulations & 22 & $34.4 \%$ \\
Financing & 14 & $21.9 \%$ \\
Insufficient market interest & 11 & $17.2 \%$ \\
Neighborhood opposition & 9 & $14.1 \%$ \\
Other & 8 & $12.4 \%$ \\
\hline Total & 64 & $100 \%$ \\
\hline Did not answer & 43 & - \\
\hline Total & 107 & -
\end{tabular}

However, results indicate that all challenges except financing were significantly different between 2004 and 2017 results. Interestingly, the four (local regulations, neighborhood opposition, insufficient market and other) are perceived as challenges by less respondents in 2017 than in 2004 .

Based on the survey question asking respondents to rank challenges, the first and second most significant challenge rankings were compared to the 2004 survey questions asking for respondents to select the most and second most significant challenge. Table 13 summarizes the responses of the most significant challenge from 2004 to 2017 . Local regulations are the most frequently selected as the most significant challenge. Comparing the overall rankings from each year results in a X2 of 11.212 and a $p$ value of 0.024 suggesting that the ranking of 2004 most significant challenge is significantly different than that of 2017. Again, respondents ranked local regulations the most significant, but less by less people in 2017. More people in 2017 perceived financing and insufficient market interest as the most significant challenge.

Table 14 summarizes the responses of the second most significant challenge from 2004 to 2017. Again, regulations are still the most frequently selected as the second most significant challenge. Comparing the overall rankings from each year results in a $\mathrm{X} 2$ of 2.738 and a $p$ value of 0.603 suggesting that the results from 2004 are not significantly different from 2017.
TABLE 11 | Frequency of second most significant Challenge.

\begin{tabular}{lcc}
- & Frequency & Percent \\
\hline Local regulations & 21 & $32.8 \%$ \\
Neighborhood opposition & 19 & $29.7 \%$ \\
Financing & 14 & $21.9 \%$ \\
Insufficient market interest & 7 & $11.0 \%$ \\
Other & 3 & $4.6 \%$ \\
\hline Total & 64 & $100 \%$ \\
\hline Did not answer & 43 & - \\
\hline Total & 107 & - \\
\hline
\end{tabular}

\section{DISCUSSION}

Although the intent was to compare the same population over time, due to access by the different researchers, the two time period's populations were different: developers and planners versus construction managers and architects. Depending on the type of project contract, construction managers and architects can become involved in the project at different times. Typically, architects are engaged by developers before construction managers, but not always. Construction managers have been engaged earlier in planning phases resulting in more successful completion of projects (Moore, 2013). These variations in project involvement could potentially affect the challenges that each population encounters. How-ever, it is still important to understand the frequency of these challenges, regardless of population, as they are still experienced around the same type of projects-mixed-use developments.

The initial research question regarding current challenges to mixed-use development asked for all challenges and barriers encountered, which was summarized in Table 7.

The four provided challenges (insufficient market interest, local regulations, securing financing, and neighborhood opposition) were primarily selected as expected, however the most interesting findings came from respondent's written 
TABLE 12 | Changes of percent of challenges encountered from 2004 to 2017.

\begin{tabular}{lcccc}
\hline $\boldsymbol{-}$ & $\mathbf{2 0 0 4}$ & $\mathbf{2 0 1 7}$ & $\mathbf{X}^{\mathbf{2}}$ & $\boldsymbol{p}$ \\
\hline Local regulations & $76.6 \%$ & $50.5 \%$ & 32.267 & 0.000 \\
Neighborhood opposition & $58.3 \% \mathrm{e}$ & $37.4 \%$ & 16.415 & 0.000 \\
Insufficient market interest & $25.6 \%$ & $13.1 \%$ & 8.069 & 0.005 \\
Other & $28.1 \%$ & $16.8 \%$ & 6.076 & 0.014 \\
Financing & $34.5 \%$ & $37.4 \%$ & 0.342 & 0.559
\end{tabular}

TABLE 13 | Changes of percent of most significant challenges encountered from 2004 to 2017.

\begin{tabular}{lcc}
\hline- & $\mathbf{2 0 0 4}$ & $\mathbf{2 0 1 7}$ \\
\hline Local regulations & $42.6 \%$ & $34.4 \%$ \\
Financing & $9.1 \%$ & $21.9 \%$ \\
Insufficient market interest & $15.0 \%$ & $17.2 \%$ \\
Neighborhood opposition & $17.5 \%$ & $14.1 \%$ \\
Other & $15.8 \%$ & $12.4 \%$ \\
\hline Total & $100 \%$ & $100 \%$
\end{tabular}

$2004 \mathrm{n}=693$ (14 did not answer). $2017 \mathrm{n}=107$ (43 did not answer).

TABLE 14 | Changes of percent of second most significant challenges encountered from 2004 to 2017.

\begin{tabular}{lcc}
\hline- & $\mathbf{2 0 0 4}$ & $\mathbf{2 0 1 7}$ \\
\hline Local regulations & $31.0 \%$ & $32.8 \%$ \\
Neighborhood opposition & $34.3 \%$ & $29.7 \%$ \\
Financing & $18.4 \%$ & $21.9 \%$ \\
Insufficient market interest & $8.4 \%$ & $11.0 \%$ \\
Other & $7.9 \%$ & $4.6 \%$ \\
\hline Total & $100 \%$ & $100 \%$
\end{tabular}

$2004 \mathrm{n}=693$ (35 did not answer). $2017 \mathrm{n}=107$ (43 did not answer).

submission for the "other" se-lection. While there are several challenges written in, three new challenges were discovered compared to the 2004 survey:

- keep up with demand and growth

- lack of implementation knowledge and development modeling

- these projects are becoming harder for smaller firms

Other challenges were also written in, but are expected from the literature review and 2004 survey; included financial risk is too high, market saturation, complexity of construction and design, no retail involvement, lack of land and land costs, insufficient developer interest, and these projects are not the norm in their NW market.

Local regulations is ranked the most significant and second most significant challenge. In order after regulations, the ranking of the most significant challenge are financing, in-sufficient market interest, neighborhood opposition, and the other category. In order after regulations, the ranking of the second most significant challenges are neighborhood op-position, financing, insufficient market interest, and the other category.

\section{Difference From 2004 and 2017}

In analyzing the differences from 2004 to 2017, the percent of the frequencies encountered for each of the years were compared, these are summarized in Table 12. As mentioned above, there are three new challenges not mentioned in 2004. All of the challenges saw a significant decrease $(p \leq 0.05)$ in the proportion of people who encountered these as challenges, except for the financing challenge. This may be for a few reasons: regulators and people in the local community are becoming more familiar with mixed-use developments. Regulators are understanding how to better accommodate these types of construction and are better prepared to handle them. The local community has changed their wants and enjoy the ease and convenience of a live-workplay environment. However, the other explanation for the significant change in encounters is simply the populations that were reached. The 2017 population was compromised of mainly general contractors and architects who may not be as involved in the early planning stages of mixed-use development and therefore may not encounter as many challenges.

When looking at the ranking of the challenges, both in 2004 and 2017 each year the first and second most significant rankings slightly change, Table 13 and 14 shows the differ-ences in percentage of ranking. However, only the most significant ranking saw a significant change with the overall $p$ value under 0.05 .

The analysis of the data from this research has provided several interesting results. First, the new challenges identified through the "other" designation provides insight into the current market within the last few years. Not being able to keep up with demand for construction can occur from a few possibilities. Lack of labor force is reasonably the most significant cause, both in manual and office labor. (Baiden et al., 2006). The average labor participation rate in the United States for January through June of 2017 is $62.8 \%$, a $5.4 \%$ decrease in the past 10 years, part of an ongoing trend of the past several decades. However, the construction industry perhaps has been hit the hardest; according to several news organizations such as Forbes (Beyer, 2017), Fox Business (Grant, 2017), CNBC (Olick, 2017), Slate (Gross, 2017), and the like have reported on the ongoing shortage of construction labor. This shortage has continued to decline, especially in the last year (Valenti, 2021).

The difficulty of securing financing can also cause issue with supplying demand as does limited land availability. Requesting a development model solidifies one of the main is-sues with mixeduse development in that project planning best practices, unfortunately, do not always work with these projects (City planning, 2016). Constructing an exact replica of a successful project in a different area can result in a drastically different outcome. The community and economic wants and needs must be identified in order to plan for the most successful uses within the development. The last new challenge identified was that it is harder for smaller firms to participate in these types of projects, which can be explained by the other new challenges. A smaller 
firm cannot always compete with larger firms (Valenti, 2021). High hourly wages and complete benefits can be more arduous for a smaller firm to offer, especially in comparison to larger firms. Further, financing, insurance, and bonds for construction is based on firm experience and size, thus it is more difficult for a smaller firm to actively complete with a larger firm on these projects. While it may be easy for a small firm to complete a single use project, the combination and size of a mixed-use development can make it too difficult for these firms.

Local regulations have remained the most significant challenge, but its frequency has significantly decreased. Neighborhood opposition has also changed since 2004, decreasing in ranking as a challenge. The old fashion idea of the "American Dream" has changed from a suburban house with a white picket fence (Govindarajan et al., 2016). This change could be driven by younger generations who either do not want or cannot afford their own transportation, more sustainable communities, be more mobile (not owning a house), have less maintenance association with a suburban home, and/or wish to support smaller, more local businesses. The appeal of a "livework-play" community also attracts older generations whose children are now out of the house and may have the same wants that younger people have, as listed above. Also, those whose health may prevent them being able to drive and wish to avoid isolation are also attracted to mixed-use neighborhoods where amenities are more easily accessible. A 2020 survey by the National Association of Realtors (National Association of Realtors, 2020) shows that all age groups, including older generations, show more interest in walkability near their home and less focused on access to highways. However, the survey does show that $60 \%$ of people surveyed want a larger yard with more outdoor space and less people around (National Association of Realtors, 2020).

\section{Recommendations}

While this research identified new and changes of significance in challenges, there is further data that should be collected. First, more planners and developers need to be reached to survey so that there is sufficient data in order to statistically determine any differences in the view and experience of challenges. Further, interviews should be completed in order to better understand these challenges and what has been done to overcome them, specifically related to local regulations and securing financing as these are the top two most significant challenges.

More data is also needed to discover why demand cannot be met, if this is actually an emerging challenge that is widespread, and if this is an issue specifically related to mixed-use developments or all construction projects in general. The cause of this challenge, whether it is being able to secure financing, having proposals rejected, lack of labor force, or something completely different, will drastically affect the way in which it is over-come.

Local regulations have been an ongoing issue for mixed-use development. Two main actions should occur to help combat this issue: policy change and education. All roles should be provided more resources in order to better understand mixed-use development, their benefits, and how they can help streamline the implementation process, particularly where mixed-use is a new concept to a community. Educating each role of all perspectives and challenges is important for any interdisciplinary team, especially in this these types of projects. When all parties can understand each other better, issues can be more easily and quickly solved. With education, policy change should be encouraged as well. As presented in the literature review, other countrie's zoning are much more mixed-use friendly, have less strict definitions of zoning/classes to allow for mixed-use without amendments or need for rezoning approval and there are often public/private partner-ships to aid in starting and completing a project. This type of partnership aids in the is-sue of securing financing for a project. Financial regulations have caused the approval process for all types of loans to be more difficult. Changes in financial regulations are more difficult to achieve, but public/private partnerships can help to alleviate some of the financial strain for these projects. Providing more educational information will also help banks make more educated decisions on lending and overall polices. However, before being able to provide a rich context-based resource to those participating in mixed-use development, more research must be completed, as described above.

Further, research should be conducted on the interconnectedness of the challenges. For example, the inability to secure financing, delays due to regulations, and lack of labor force may contribute to not being able to meet demand. Neighborhood opposition may affect the opinion of the city planners and how they enforce the local regulations. Local regulations may impact the availability to secure financing through a bank. Other relationships may exist such as these that are unknown. Understanding these connections will further lend itself to the understanding of the cause and more importantly, the solution of these challenges.

\section{DATA AVAILABILITY STATEMENT}

The raw data supporting the conclusion of this article will be made available by the authors, without undue reservation.

\section{ETHICS STATEMENT}

The studies involving human participants were reviewed and approved by Purdue University. The patients/participants provided their written informed consent to participate in this study.

\section{AUTHOR CONTRIBUTIONS}

JM researched and wrote the entire paper. 


\section{REFERENCES}

Anders, M. (2004). Understanding and Balancing Mixed-Use Schemes: The Key to Creating Successful Communities. J. Retail Leis. Property 3 (4), 353-364. doi:10.1057/palgrave.rlp.5090190

Baiden, B. K., Price, A. D. F., and Dainty, A. R. J. (2006). The Extent of Team Integration within Construction Projects. Int. J. Project Manag. 24, 13-23. doi:10.1016/j.jproman.2005.05.001

Beyer, S. (2017). America's Housing Construction Labor Shortage Continues. Forbes. Retrieved from: https://www.forbes.com/sites/scottbeyer/2017/04/29/ americas-housing-construction-labor-shortage-continues/\#66de0314706c (Accessed March 9, 2016)

Brewer, K., and Grant, J. L. (2015). Seeking Density and Mix in the Suburbs: Challenges for Mid-sized Cities. Plann. Theor. Pract. 16 (2), 151-168. doi:10.1080/14649357.2015.1011216

Buildings. (2009). Mixed-use Facilities Are a Productive Use of Space, and They Add viatality to Urban Areas - but Not without Challenges. Retrieved from: http://www.buildings.com/article-details/articleid/9004/title/the-challengesand-benefits-of-mixed-use-facilities

Chinburg Properies (). Commercial Rental Real Estate: The Top 5 Benefits to Locating Your Business in a Mixed-Use Com-Mercial/Residential Building. Retrieved from: https://chinburg.com/commercial-rental-real-estate-the-top5-benefits-to-mixed-use-space-for-businesses/ (Accessed March 9, 2016).

City planning. (2016). Dictionary.Com Unabridged. Retrieved from: http://www. dictionary.com/browse/city-planning

Efficient Gov. (2015). Pros \& Cons: Mixed-Use Developments. Retrieved from: https://efficientgov.com/blog/2015/06/24/pros-cons-mixed-use-developments/ (Accessed March 9, 2016).

Govindarajan, V., Lev, B., Srivastava, A., and Luminita, E. (2016). The Gap between Large and Small Companies Growing. Why? Harv. Business Rev.

Grant, J. (2002). Mixed Use in Theory and Practice:Canadian Experience with Implementing a Planning Principle. J. Am. Plann. Assoc. 68 (1), 71-84. doi:10.1080/01944360208977192

Grant, J., and Perrott, K. (2011). Where Is the Café? the Challenge of Making Retail Uses Viable in Mixed-Use Suburban Developments. Urban Stud. 48 (1), 177-195. doi:10.1177/0042098009360232

Grant, P. (2017). Labor Shortage Squeezes Builders. CNBC. Retrieved from: http:// www.foxbusiness.com/features/2017/05/06/labor-shortage-squeezes-builders. html (Accessed March 9, 2016)

Gross, D. (2017). There's No Such Thing as Jobs Americans Won't Do. Slate. New York, NY: Retrieved.

Hoppenbrouwer, E., and Louw, E. (2005). Mixed-use Development: Theory and Practice in Amsterdam's Eastern Docklands. Eur. Plann. Stud. 13 (7), 967-983. doi:10.1080/09654310500242048

Koch, D. (2004). Looking up. Retail Traffic 33 (1238-40), 42-43.

Kong, H., Sui, D. Z., Tong, X., and Wang, X. (2015). Paths to Mixed-Use Development: A Case Study of Southern Changping in Beijing, China. Cities 44, 94-103. doi:10.1016/j.cities.2015.01.003

Lamb, I. (2012). Experts Discuss the Benefits of Mixed-Use Development. Retrieved from: http://www.cvilletomorrow.org/news/article/12796-mixeduse-development/ (Accessed March 9, 2016).

Lau, S. S. Y., Giridharan, R., and Ganesan, S. (2005). Multiple and Intensive Land Use: Case Studies in Hong Kong. Habitat Int. 29 (3), 527-546. doi:10.1016/ j.habitatint.2004.04.007

Lee, W. (2020). Major Issues in Commuting Efficiency: A Literature Review. Pa. Geographer 58 (1), 25-34.

Leonard, B., and Cumbelich, J. (2014). Mixed Use: A Mixed bag;Whysome MixedUse Projects Succeed and Other Fail - the Right Street-Level Retail Can Make All the Difference. Retrieved from: http://www.chainstoreage.com/article/ mixed-use-mixed-bag (Accessed March 9, 2016)

Levine, J., and Inam, A. (2004). The Market for Transportation-Land Use Integration: Do Developers Want Smarter Growth Than Regulations Allow? Transportation 31 (4), 409-427. doi:10.1023/B: PORT.0000037086.33893.9f
Mahmoudi Farahani, L., Beynon, D., and Garduno Freeman, C. (2018). The Need for Diversity of Uses in Suburban Neighbourhood Centres. Urban Des. Int. 23 (2), 86-101. doi:10.1057/s41289-017-0052-x

Moore, S. (2013). What's Wrong with Best Practice? Questioning the Typification of New Urbanism. Urban Stud. 50 (11), 2371-2387. doi:10.1177/ 0042098013478231

National Association of Realtors (2020). Community and Transportation Preference Survey. Retrieved from: https://cdn.nar.realtor/sites/default/files/ documents/2020-transportation-survey-analysis-slides.pdf (Accessed March 9, 2016)

Newcomb, T. (2015). Mixed-Use, Multi-Family Projects See Uptick. ENR: Eng. News-Record 275 (13), 69

Niemira, M. P. (2007). The Concept and Drivers of Mixed-Use Development: Insights from a Cross-Organizational Membership Survey. Res. Rev. 4 (1), 54, 2007 . Retrieved from: http://www.docstoc.com/docs/38713816/Features-TheConcept-and-Drivers-of-Mixed-Use-Development

Olick, D. (2017).Homebuilders Struggle to Fill Jobs 'Americans Don't Want'. Retrieved from: http://www.cnbc.com/2017/03/29/homebuilders-struggle-tofill-jobs-americans-dont-want.html (Accessed March 9, 2016)

Rabianski, J., Gibler, K., Tidwell, O. A., and Clements III, J. S. (2009). Mixed-Use Development: A Call for Research. J. Real Estate Lit. 17 (2), 205-230. doi:10.1080/10835547.2009.12090251

Rowley, A. (1996). Mixed-use Development: Ambiguous Concept, Simplistic Analysis and Wishful Thinking? Plann. Pract. Res. 11 (1), 85-98. doi:10.1080/02697459650036477

Slowly, K. (2016). Building a 'sense of Community': Why Mixed-Use Developments Are Sprouting up across the US. Retrieved from: http://www. constructiondive.com/news/building-a-sense-of-community-why-mixed-usedevelopments-are-sprouting-u/421386/ (Accessed March 9, 2016).

Taleai, M., Sharifi, A., Sliuzas, R., and Mesgari, M. (2007). Evaluating the Compatibility of Multi-Functional and Intensive Urban Land Uses. Int. J. Appl. Earth Observation Geoinformation 9 (4), 375-391. doi:10.1016/ j.jag.2006.12.002

University of Delaware Delaware Complete Communities Toolbox (n.d.). Benefits of Mixed-Use Development. Retrieved fro: http://sites.udel.edu/completecommunities/ planning/landuse/mixed-use-benefits/ (Accessed March 9, 2016).

Urban Land Institute. (2011). Mixed-use Development 101: The Design MixedUse Buildings [PowerPoint Slides]. Retrieved from: http://triangle.uli.org/wpcontent/uploads/sites/54/2013/01/Design-of-Mixed-Use-Buildings.pdf (Accessed March 9, 2016)

Useful Community Development (2017). Mixed-use Development Delivers Great Benefits. Retrieved from: http://www.useful-community-development.org/ mixed-use-development.html (Accessed March 9, 2016)

Valenti, A. (2021). Price Hikes, Labor Shortages Slow Construction Industry's Recovery. New Orleans: New Orleans CityBusiness.

Woo, Y.-E., and Cho, G.-H. (2018). Impact of the Surrounding Built Environment on Energy Consumption in Mixed-Use Building. Sustainability 10 (3), 832. doi:10.3390/su10030832

Conflict of Interest: The authors declare that the research was conducted in the absence of any commercial or financial relationships that could be construed as a potential conflict of interest.

Publisher's Note: All claims expressed in this article are solely those of the authors and do not necessarily represent those of their affiliated organizations, or those of the publisher, the editors and the reviewers. Any product that may be evaluated in this article, or claim that may be made by its manufacturer, is not guaranteed or endorsed by the publisher.

Copyright $(\odot 2021$ Metzinger. This is an open-access article distributed under the terms of the Creative Commons Attribution License (CC BY). The use, distribution or reproduction in other forums is permitted, provided the original author $(s)$ and the copyright owner(s) are credited and that the original publication in this journal is cited, in accordance with accepted academic practice. No use, distribution or reproduction is permitted which does not comply with these terms. 